\title{
Viabilidade produtiva e econômica do consórcio entre chicória e rúcula em função da época de plantio
}

\author{
Arthur Bernardes Cecílio Filho ${ }^{1,3}$; Caciana C Costa ${ }^{2}$; Bráulio Luciano A Rezende ${ }^{1,4}$; Ricardo van Leeuwen ${ }^{5}$ \\ ${ }^{1}$ UNESP-FCAV, Dep ${ }^{\text {to }}$ Prod Vegetal, Rod. Prof. Paulo D. Castellane s/n, 14884-900 Jaboticabal-SP; ${ }^{2}$ Univ. Fed. Campina Grande-CCTA, \\ R. Cel. João Leite 517, Centro, 58840-000 Pombal-PB; ${ }^{3}$ Bolsista CNPq; ${ }^{4}$ Pós-graduando Agronomia, Prod. Vegetal; ${ }^{5}$ Eng. Agrônomo; \\ rutra@fcav.unesp.br;
}

\section{RESUMO}

Para avaliar o efeito da consorciação das culturas de chicória e da rúcula sobre suas produtividades, foi conduzido um experimento de 23/07 a 12/11/03, na UNESP-FCAV. Os 11 tratamentos foram constituídos por consórcios de chicória e rúcula, estabelecidos com a semeadura da rúcula aos $0 ; 5 ; 10 ; 15$ e 20 dias após o transplante (DAT) da chicória e pelas monoculturas nas respectivas épocas de consórcio. O delineamento experimental foi o de blocos ao acaso, com quatro repetições. A rúcula, independente da época em que foi semeada, não influenciou a produtividade da chicória. A matéria fresca da parte aérea da rúcula (MFRu) foi influenciada significativamente pela interação dos fatores avaliados. Quanto mais atrasada a semeadura da rúcula em relação ao transplante da chicória, menor foi a MFRu. A produção de MFRu em consórcio não diferiu da obtida em monocultura quando a semeadura da rúcula foi realizada até 10 DAT da chicória. O melhor consórcio sob o ponto de vista do índice de eficiência de uso da área $(E U A=2,29)$, da receita líquida $(\mathrm{R} \$ 75.873,09 / \mathrm{ha})$ e da taxa de retorno $(\mathrm{TR}=14,17)$ foi obtido em consórcio estabelecido com a semeadura da rúcula no mesmo dia do transplante da chicória.

Palavras-chave: Cichorium endivia, Eruca sativa, sistema de cultivo, uso eficiente da área, consorciação, rentabilidade.

\section{ABSTRACT}

Yield and economic feasibility of the endive and rocket intercropping, as a result of the planting time

The experiment was carried out in São Paulo State, Brazil, aiming to evaluate the effect of the intercropping on endive and rocket yields. The 11 treatments were constituted from endive and rocket intercropping, established at $0 ; 5 ; 10 ; 15$ and 20 days after the endive transplant (DAET) and also the monocultures for all time of intercropping. The experimental design were randomized complete blocks, with eleven treatments and four replications. Independent of sowing time of rocket, the endive yield was not influenced. The fresh matter of the aerial part of the rocket (FMR) was significantly influenced by the interaction of the assessed factors. The later sowing of the rocket in relation to the chicory transplant, the smaller was FMR. The production of FMR in intercropping didn't differ from that obtained in monoculture when the sowing of the rocket was accomplished at 10 DAT of endive. The best intercropping in terms of efficient use of the area $(\mathrm{EUA}=2.29)$, net revenue $(\mathrm{R} \$ 75.873,09$ / ha) and rate of return $(R R=14.17)$ was obtained when the rocket sowing in intercropping was established on the same day as the chicory transplant.

Keywords: Cichorium endivia, Eruca sativa, cropping system, land equivalent ratio, intercropping, profitability.

\section{(Recebido para publicação em 19 de março de 2007; aceito em 27 de junho de 2008)}

$\mathrm{S}$ egundo Yokota (2002), nas áreas que se concentram próximo aos centros consumidores, sobretudo nos cinturões verdes das grandes cidades, a produção das hortaliças é realizada na modalidade de jardinagem oriental. Este modelo caracteriza-se pelo uso intensivo do solo e da mão-de-obra, e as principais hortaliças cultivadas são o tomate, a cenoura e as folhosas, entre as quais a chicória e a rúcula.

Recentemente, pesquisas têm proposto o cultivo consorciado de hortaliças. Neste, além da maior produção de alimentos por unidade de área, proporciona maior diversidade biológica, maior proteção do solo, maior eficiência de uso da terra e maior aproveitamento de recursos e insumos utilizados nos cultivos (Rezende et al., 2005). No entanto, estudos para maximização da eficiência do consórcio são necessários, principalmente, quanto à época da instalação do consórcio. As produtividades das culturas consorciadas podem ser afetadas pelo período de convivência das espécies (Cecílio Filho \& May, 2002).

Ainda que seja constatado aumento da produtividade em consórcio em relação às monoculturas, há necessidade de se realizar a avaliação econômica comparativa dos sistemas de cultivo. Redução na população da hortaliça considerada secundária no consórcio, assim como prejuízo no valor comercial (classificação) poderão ocorrer e, assim, não confirmar a vantagem produtiva do consórcio sobre a monocultura.

Entre as hortaliças folhosas, alface e a rúcula são freqüientemente empregadas em consórcios entre si, ou delas com outras hortaliças e raramente temse o uso da chicória.

O presente trabalho objetivou avaliar a produtividade e a viabilidade econômica de consórcios de chicória e rúcula, em função da época de estabelecimento do cultivo consorciado.

\section{MATERIAL E MÉTODOS}

$\mathrm{O}$ experimento foi conduzido em campo, de 23/07 a 12/11/03, na UNESP, em Jaboticabal-SP, em Latossolo Vermelho Eutroférrico típico de textura muito argilosa, A moderado caulinítico-oxídico. A análise química do solo apresentou $\mathrm{pH}\left(\mathrm{CaCl}_{2}\right)$ de 5,3; $19 \mathrm{~g} \mathrm{dm}^{-3}$ de matéria orgânica, 98 $\mathrm{mg} \mathrm{dm}{ }^{-3} \mathrm{de} \mathrm{P}$ (resina), 3, 1; $38 \mathrm{e} 7 \mathrm{mmol}$ c $\mathrm{dm}^{-3}$, respectivamente, de $\mathrm{K}, \mathrm{Ca}, \mathrm{Mg}$ e V\% de 72 . 
Foram avaliados 11 tratamentos que corresponderam aos consórcios de chicória (Cichorium endivia) e rúcula (Eruca sativa) estabelecidas nas épocas $0 ; 5 ; 10 ; 15 ;$ e 20 dias após o transplante (DAT) da chicória; monoculturas da chicória e de rúcula, estabelecidas nas mesmas épocas de estabelecimento dos consórcios, a fim de isolar possível efeito da época de plantio.

O experimento foi conduzido sob delineamento de blocos casualizados (DBC), com quatro repetições. A unidade experimental foi constituída por área total de $2,4 \mathrm{~m}^{2}$. A bordadura para a cultura da chicória foi representada pelas plantas localizadas no início e final de cada linha de cultivo. Para a rúcula, foram consideradas bordaduras, 0,20 $\mathrm{m}$ de cada extremidade das linhas de cultivo.

O preparo do solo constou de aração, gradagem e formação dos canteiros com rotoencanteirador. Calagem não foi realizada. As adubações de plantio e de cobertura foram feitas com base nas recomendações de Trani et al. (1997). Para a cultura da chicória, no plantio foram aplicados $100 \mathrm{~g} / \mathrm{m}^{2}$ do fertilizante $\mathrm{N}-\mathrm{P}_{2} \mathrm{O}_{5}-\mathrm{K}_{2} \mathrm{O}$ da formulação 4-30-16. As adubações de cobertura para a chicória constaram da aplicação, por planta, de $2 \mathrm{~g}$ de nitrato de amônio, aos 10 DAT, de $4 \mathrm{~g}$ de nitrato de amônio e $2 \mathrm{~g}$ de cloreto de potássio, aos 25 DAT e, aos 35 DAT, foram aplicadas $4 \mathrm{~g}$ de nitrato de amônio. Para a rúcula, a adubação de cobertura foi realizada em dois parcelamentos aos 7 e 15 dias após a emergência das plântulas, com aplicações de $10 \mathrm{~g}$ de nitrato de amônio por metro linear.

Foram utilizadas as cultivares Mariana Gigante e Folha Larga, respectivamente, para chicória e rúcula. A chicória foi semeada em bandejas de poliestireno expandido de 288 células e transplantada em 16/09/03. O espaçamento adotado para chicória foi de 0,30 m entrelinhas e 0,40 m entre plantas. A rúcula foi semeada nas entrelinhas da chicória nas diferentes épocas pré-estabelecidas, sendo procedido desbaste aos 10 dias após a emergência, para estabelecer o espaçamento de 0,05 $\mathrm{m}$ entre plantas. $\mathrm{Na}$ monocultura da rúcula, o espaçamento entrelinhas foi de 0,25 m, mantendo-se o espaçamento entre plantas usado no consórcio. A colheita da chicória foi realizada aos 57 DAT (12/11/03) e a rúcula aos 35 dias após a semeadura (21/10/03), sendo considerado como comercial a rúcula com altura (medida após a colheita) superior a $20 \mathrm{~cm}$.

Na cultura da chicória as características matéria fresca e diâmetro da parte aérea foram avaliadas separadamente para plantas situadas nas laterais (MFCex e Dex) e nas duas linhas internas do canteiro (MFCin e Din). Para a rúcula, a matéria fresca da parte aérea (MFRu) foi obtida de plantas presentes em $1 \mathrm{~m}$ de cada linha da parcela. Avaliou-se, também, a cada 5 dias, o comprimento das projeções das partes aéreas da chicória e da rúcula no sentido perpendicular à linha de plantio, de modo a caracterizar a ocupação do terreno e início de competição das culturas pelo espaço.

As análises estatísticas foram realizadas pelo programa SAS. Para as características da chicória, a análise de variância foi realizada como DBC com 6 tratamentos (5 consórcios e 1 monocultura) e quatro repetições. Para rúcula, também sob $\mathrm{DBC}$, porém em esquema fatorial $5 \times 2$, ou seja, cinco épocas de semeadura da rúcula em dois sistemas de cultivo (monocultura e consórcio). As médias relativas às características de rúcula foram submetidas à regressão polinomial para ajuste de equações.

Os índices agroeconômicos usados para avaliar a eficiência dos sistemas consorciados foram: índice de eficiência de uso da área (EUA), receita bruta $(\mathrm{RB})$, receita líquida (RL) e taxa de retorno (TR). Para o cálculo do índice EUA foi utilizada a fórmula proposta por Willey (1979): EUA = (Yab/Yaa $)+$ (Yba/Ybb), onde, Yab é a produtividade da cultura "a" em consórcio com a cultura "b"; Yba é a produtividade da cultura "b" em consórcio com a cultura "a"; Yaa é a produtividade da cultura "a" em monocultura e Ybb é a produção da cultura "b" em monocultura. Para o cálculo dos índices foram utilizadas as produtividades das culturas de chicória e rúcula expressas em área $\left(\mathrm{kg} \mathrm{ha}^{-1}\right)$, uma vez que existe diferença de estande em função do sistema de cultivo.
O custo operacional total das culturas nos sistemas de cultivo (consórcio e monocultura) foi resultante dos custos das operações e insumos, obtidos no experimento e no comércio de Jaboticabal-SP, respectivamente, e estimados para 1 ha. Foram considerados os preços nominais de setembro de 2005 de todos os itens do custo operacional total e salários, transformados em preços reais utilizando-se o IGP-DI (Índice Geral de Preços - Disponibilidade Interna), publicado pela Fundação Getúlio Vargas, com base em dezembro de 2005 (FUNDAÇÃO GETÚLIO VARGAS, 2005). A estimativa do custo de produção das culturas não levou em consideração os gastos com comercialização dos produtos.

Para ambas as culturas, o cálculo da receita bruta $(\mathrm{RB})$ dos tratamentos considerou o preço nominal médio no atacado no mês da colheita da rúcula (outubro) e da chicória (novembro), transformados em reais de dezembro de 2005 pelo IGP-DI, praticado na CEAGESP, foi de $\mathrm{R} \$ 1,86 / \mathrm{kg}$ para a chicória e $\mathrm{R} \$$ $1,04 / \mathrm{kg}$ para rúcula. A receita líquida foi obtida pela diferença entre a receita bruta e o custo operacional total (COT). A taxa de retorno foi calculada mediante a relação entre a RB e COT.

\section{RESULTADOS E DISCUSSÃO}

A produtividade média obtida na cultura de chicória foi de $4,062 \mathrm{~kg} \mathrm{~m}^{-2} \mathrm{e}$ a produção comercial nas classes 10, 12 e 15 foram 3,29; 26,78 e 69,93\%, respectivamente.

O diâmetro e matéria fresca de plantas de chicória localizadas nas linhas laterais (Dex e MFCex) e internas (Din e MFCin) do canteiro não foram influenciados pelo consórcio ou por épocas de semeadura da rúcula. A média do Dex e Din foi de 35,46 e 36,55 cm planta $^{-1}$, e para a MFCex e MFCin foi de 460,63 e 545,49 g planta $^{-1}$, respectivamente.

Em função dos resultados, pode-se afirmar que a presença da rúcula, independente da época em que foi semeada, não afetou o crescimento da chicória. Ciclo muito curto, pequenas altura, área foliar e projeção de suas folhas sobre a chicória, foram características que permitiram que a chicória crescesse sem 


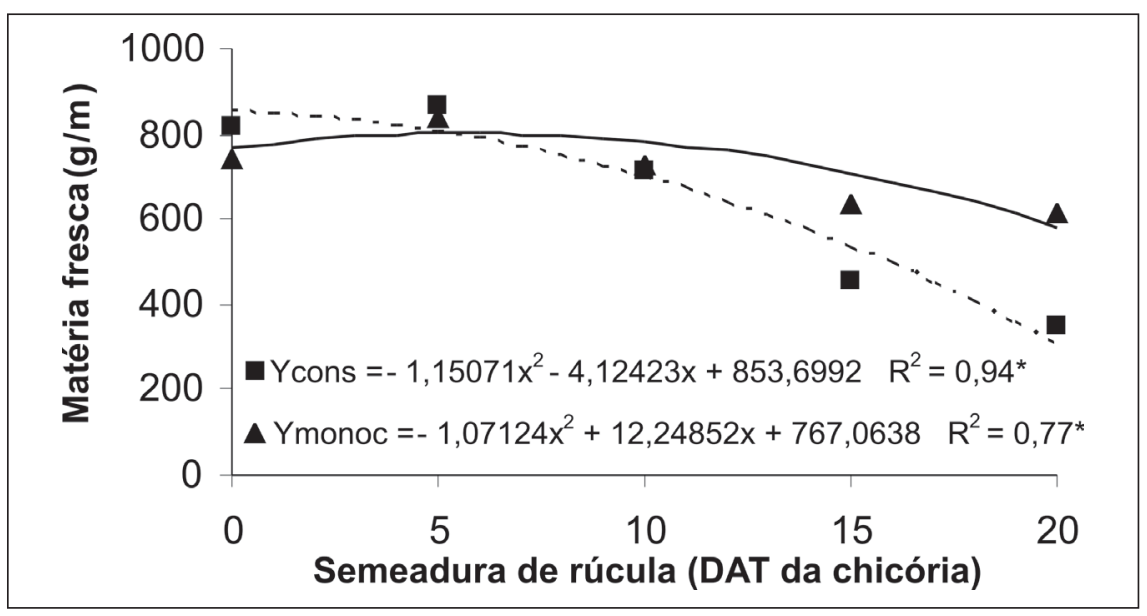

Figura 1. Matéria fresca da parte aérea da rúcula em função da interação sistema de cultivo e época de semeadura da rúcula, em dias após o transplante (DAT) da chicória. (Fresh matter of the aerial part of the rocket in function of the interaction cultivation system and sowing time of the rocket, in days after the transplant (DAT) of the endive). Jaboticabal, UNESP, 2003.

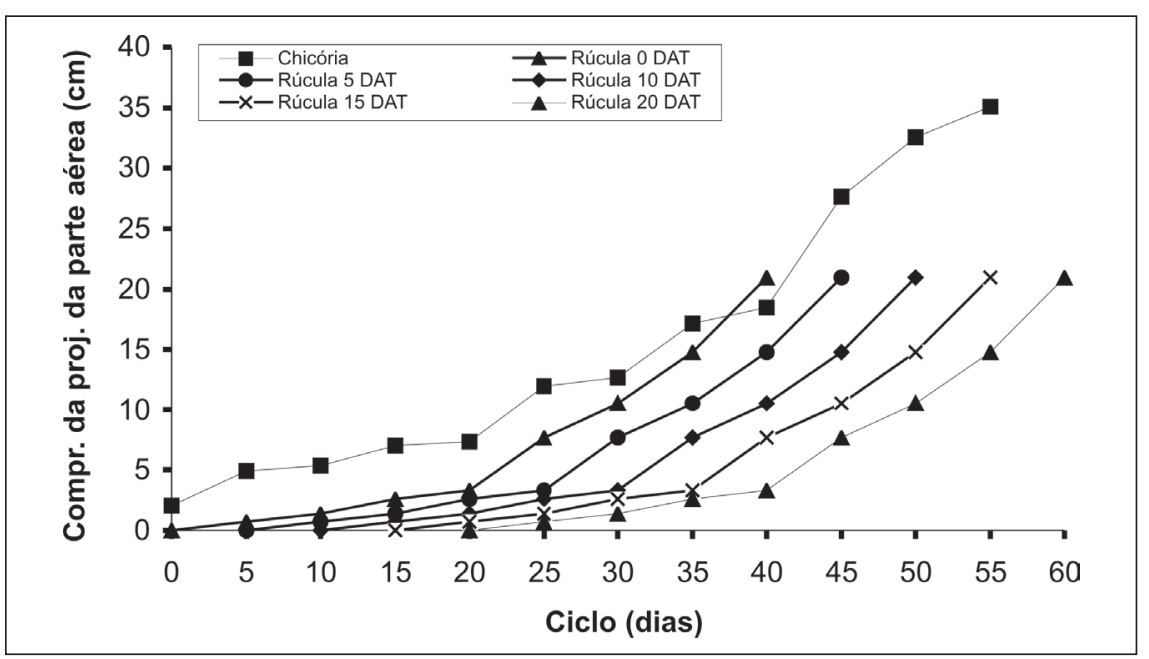

Figura 2. Comprimento da projeção da parte aérea da chicória e da rúcula, no sentido perpendicular à linha de plantio, no decorrer do ciclo. (Length of the projection of the aerial part of the endive and of the rocket, in the perpendicular sense to the planting line, in elapsing of the cycle). Jaboticabal, UNESP, 2003.

sofrer a interferência da rúcula. Assim, pode-se afirmar que a chicória apresentou-se indiferente à presença da rúcula.

Em consórcios com beterraba (Nardin et al., 2002a,b), com pimentão e repolho (Rezende et al., 2006) e com alfaces crespa, lisa e americana, neste caso dependendo da época de cultivo (estação do ano) e da época de semeadura da rúcula em relação à alface (Costa et al. 2003a, 2003b), a rúcula, assim como neste trabalho, não influenciou a produtividade das culturas em associação. Por outro lado, Basso (2000) observou que houve redução acentuada na de cultivo e época de semeadura da rúcula em relação à chicória.

Em monocultura, houve ajuste de equação polinomial de segundo grau para a MFRu em resposta ao atraso da semeadura (Figura 1). A MFRu aumentou quando esta foi semeada até 6 DAT da chicória, atingindo o máximo de 802 $\mathrm{g} \mathrm{m}^{-1}$. A partir de então, decréscimos seguidos foram observados até a semeadura da rúcula $20 \mathrm{DAT}$, obtendo-se nesta somente $583,54 \mathrm{~g} \mathrm{~m}^{-1}$, o correspondente a uma redução de $27 \%$. Esta redução pode ser atribuída a uma piora nas condições ambientais para a cultura da rúcula. Sob cultivo consorciado, o ajuste observado da MFRu também foi de uma equação de segundo grau, porém com reduções sucessivas na MFRu já a partir de 1 dia de atraso na semeadura em relação ao transplante da chicória (Figura 1). Assim, máxima MFRu em consórcio $\left(853,7 \mathrm{~g} \mathrm{~m}^{-1}\right)$ foi obtida com a semeadura da rúcula 0 DAT da chicória e, aos 20 DAT, o mínimo de $310,9 \mathrm{~g}$ $\mathrm{m}^{-1}$. Portanto, no consórcio, a competição interespecífica sobrepôs-se a qualquer outro fator ambiental. Sob condições de consórcio, a redução percebida entre 0 (máxima MFRu) e 20 DAT (mínima MFRu) foi de $63,6 \%$ muito superior aos $27 \%$ observado entre o máximo e mínimo obtido em monocultura.

Consórcios estabelecidos com a semeadura tardia da rúcula em relação à alface crespa ('Vera') e americana ('Tainá), na primavera, também apresentaram elevadas reduções nas produtividades da rúcula, $52,53 \%$ e $60,84 \%$, respectivamente (Costa et al. 2003b).

Em consórcios que adotam culturas em linhas intercaladas, devido à maior proximidade das plantas das culturas componentes do consórcio, espera-se maior interferência de uma no ambiente da outra, estabelecendo-se, assim, maior competição interespecífica (Cecílio Filho, 2005). O manejo dos fatores de produção, tais como a densidade e o arranjo populacional e a época relativa do estabelecimento das culturas componentes do consórcio poderão minimizar a competição e maximizar a complementaridade temporal e/ou espacial das culturas.

As MFRu obtidas em monocultura e em consórcio não diferiram entre si 
quando a semeadura da rúcula foi realizada no mesmo dia do transplante da chicória a até 10 dias após (Tabela 1). Neste momento a superioridade (não significativa) da MFRu obtida na monocultura que era de $13,7 \%$ sobre a de consórcio, atingiu 40,8 e 76,5\% para semeaduras realizadas aos 15 e 20 DAT da chicória, respectivamente (Tabela 1). Portanto, a competição interespecífica não existiu ou foi muito pequena em consócios estabelecidos com a semeadura da rúcula até 10 DAT da chicória.

A crescente vantagem da monocultura sobre o consórcio foi resultado da competição entre as espécies ter ocorrido mais precocemente para a rúcula e permaneceu por mais tempo quando esta foi semeada mais tardiamente. Nas semeaduras realizadas aos 0; 5; 10; 15 e 20 DAT da chicória, o diâmetro da parte aérea desta hortaliça encontrava-se, respectivamente, com 2,1; 5,1; 6,2; 7,5 e 7,7 cm (Figura 2). Considerando que o espaçamento entrelinhas da chicória foi de $0,30 \mathrm{~m}$ e que a rúcula foi semeada em sulco situado na metade da entrelinha da chicória, tem-se 0,15 m entre a chicória e a rúcula, onde as espécies poderiam crescer sem estabelecer competição de uma para com a outra.

Na Figura 2, observa-se que, para o consórcio estabelecido com transplante da chicória e semeadura da rúcula no mesmo dia, as culturas encontraram-se a partir de 33 dias após a semeadura, pois a soma das metades das projeções das copas da chicória e da rúcula correspoderam a $0,15 \mathrm{~m}$, que era o espaço disponível entre si. Quanto mais atrasada foi a semeadura da rúcula em relação ao transplante da chicória, mais precoce foi a competição que a chicória estabeleceu sobre a rúcula e, consequientemente, maior o período de convivência sob estresse. Ou seja, enquanto a rúcula semeada a 0 DAT da chicória sofreu competição a partir de 33 dias de seu ciclo, a competição iniciou-se com 31; 30; 27 e 23 dias quando foi semeada aos $5 ; 10$; 15 e 20 DAT da chicória, respectivamente. Como a rúcula foi colhida, para todas as épocas avaliadas aos 40 dias após a semeadura, o período de convivência em competição com a chicória foi de 7; 9; 10; 13 e 17 dias, res-

Tabela 1. Matéria fresca de rúcula $\left(\mathrm{g} \mathrm{m}^{-1}\right)$ em função do sistema de cultivo e época de semeadura da rúcula, em dias após o transplante da chicória.(Fresh matter of rocket $\left(\mathrm{g} \mathrm{m}^{-1}\right)$ in function of the cultivation system and sowing time of the rocket, in days after the transplant of the endive). Jaboticabal, UNESP, 2003.

\begin{tabular}{lcccccc}
\hline \multirow{2}{*}{$\begin{array}{l}\text { Sistema de } \\
\text { cultivo }\end{array}$} & \multicolumn{5}{c}{ Época de semeadura da rúcula (dias) } & \multirow{2}{*}{ Média } \\
\cline { 2 - 6 } & $\mathbf{0}$ & $\mathbf{5}$ & $\mathbf{1 0}$ & $\mathbf{1 5}$ & $\mathbf{2 0}$ & \\
\hline Consórcio & $821,25 \mathrm{Aa}$ & $863,75 \mathrm{Aa}$ & $713,75 \mathrm{Aa}$ & $451,67 \mathrm{Bb}$ & $348,83 \mathrm{Bb}$ & $639,85 \mathrm{~b}^{1}$ \\
Monocultura & $744,69 \mathrm{ABCa}$ & $836,56 \mathrm{Aa}$ & $811,56 \mathrm{ABa}$ & $635,87 \mathrm{BCa}$ & $615,63 \mathrm{Ca}$ & $728,86 \mathrm{a}$ \\
\hline Média & $782,97 \mathrm{~A} 1$ & $850,15 \mathrm{~A}$ & $762,65 \mathrm{~A}$ & $543,77 \mathrm{~B}$ & 482,23 & $\mathrm{~B}$ \\
\hline
\end{tabular}

${ }^{1}$ Médias seguidas de maiúscula e minúsculas iguais, respectivamente, na linha e na coluna não diferem entre si pelo teste Tukey a $5 \%$ de probabilidade. (Averages followed by same capital letter and lower cases, respectively, in the line and in the column they don't differ to each other for the test Tukey to $5 \%$ of probability).

Tabela 2. Produtividades, índices de uso eficiente da área (UEA), receita bruta (RB), receita líquida (RL) e taxa de retorno (TR) de monoculturas e consórcios de chicória e rúcula. (Productivities, indexes of efficient use of the area (UEA), rude revenue (RB), liquid revenue (RL) and it rates of return (TR) of monocultures and intercroppings). Jaboticabal, UNESP, 2003.

\begin{tabular}{|c|c|c|c|c|c|c|}
\hline \multirow{2}{*}{$\begin{array}{l}\text { Sistemas de } \\
\text { cultivos }\end{array}$} & \multicolumn{2}{|c|}{ Produtividade $\left(\mathrm{kg} \mathrm{ha}^{-1}\right)^{*}$} & \multirow{2}{*}{ EUA } & RB & $\mathbf{R L}$ & \multirow{2}{*}{ TR } \\
\hline & Chicória & Rúcula & & \multicolumn{2}{|c|}{$\mathbf{R} \$ \mathrm{ha}^{-1}$} & \\
\hline \multicolumn{7}{|l|}{ Consórcios } \\
\hline 0 DAT & 34.247 & $17.246,25$ & 2,29 & $81.635,52$ & $75.873,09$ & 14,17 \\
\hline 5 DAT & 30.516 & $18.138,75$ & 1,83 & $75.624,06$ & $69.861,63$ & 13,12 \\
\hline 10 DAT & 28.195 & $14.988,75$ & 1,63 & $68.031,00$ & $62.268,57$ & 11,80 \\
\hline 15 DAT & 28.680 & $9.485,00$ & 1,52 & $63.583,60$ & $57.821,17$ & 11,03 \\
\hline 20 DAT & 25.618 & $7.325,50$ & 1,31 & $55.268,00$ & $49.505,57$ & 9,59 \\
\hline \multicolumn{7}{|l|}{ Monoculturas } \\
\hline Chicória & 28.814 & - & - & $53.594,04$ & $49.743,81$ & 13,92 \\
\hline Rúcula 0 DAT & - & $15.638,42$ & - & $16.263,95$ & $12.912,07$ & 4,85 \\
\hline Rúcula 5 DAT & - & $23.423,75$ & - & $24.360,70$ & $21.008,82$ & 7,27 \\
\hline Rúcula 10 DAT & - & $22.723,68$ & - & $23.632,63$ & $20.280,75$ & 7,05 \\
\hline Rúcula 15 DAT & - & $17.804,50$ & - & $18.516,68$ & $15.164,80$ & 5,52 \\
\hline Rúcula 20 DAT & - & $17.237,50$ & - & $17.927,00$ & $14.575,12$ & 5,34 \\
\hline
\end{tabular}

DAT $=$ Dias após o transplante da chicória; * A área efetivamente cultivada em 1 hectare foi de $7.000 \mathrm{~m}^{2}$. (DAT $=$ days after the transplanting of endive; The area indeed cultivated in 1 hectare it was of $7,000 \mathrm{~m}^{2}$.)

pectivamente, para os consórcios estabelecidos com a semeadura da rúcula aos $0 ; 5 ; 10 ; 15$ e 20 DAT da chicória.

Os índices de eficiência de uso da área (EUA) demonstraram que os cultivos consorciados foram vantajosos em relação às respectivas monoculturas (Tabela 2 ). $\mathrm{O}$ melhor índice foi obtido no consórcio estabelecido com a semeadura da rúcula a 0 DAT da chicória. Nesta condição, o índice EUA de 2,29 traduz a grande vantagem de produção das culturas em consórcio, pois para se produzir a mesma quantidade de hortaliças colhidas em 1 ha de consórcio, seria necessária uma área de 2,29 ha das monoculturas (1,145 ha para cada uma). O menor índice EUA foi obtido com a semeadura da rúcula 20 DAT da chicória, mas ainda nesta situação em que se constatou elevada competição da chicória sobre a rúcula, a superioridade na quantidade de hortaliças produzidas foi de $31 \%$. Desempenhos semelhantes ao verificado neste trabalho foram constatados para consórcios de beterraba e rúcula (Cecílio Filho et al., 2003), alface e rúcula (Costa et al., 2003 a, 2003b), alface e rabanete (Cecílio Filho \& May, 2002) e tomate e alface (Cecílio Filho, 2005), entre outros. Nestes, também verificou-se valores do índice EUA maiores com o estabelecimento das culturas no mesmo dia e redução da eficiência de uso da área do consórcio mediante atraso no plantio de uma das culturas envolvidas em relação à outra. 
O COT da chicória em monocultura foi de $\mathrm{R} \$ 3.850,23 /$ ha, de rúcula $\mathrm{R} \$ 3.351,88 /$ ha e do consórcio foi de $\mathrm{R} \$ 5.762,43 /$ ha.

O maior índice EUA $(2,29)$ proporcionou maiores receita bruta ( $\mathrm{R} \$ 81.635,52 /$ ha), receita líquida ( $\mathrm{R} \$ 75.873,09 / \mathrm{ha}) \mathrm{e}$ maior retorno econômico $(14,17)$. A receita líquida obtida em 1 ha do consórcio estabelecido com o plantio das duas culturas no mesmo dia superou em $21 \%$ a soma das rentabilidades das monoculturas de 1 ha de chicória e 1 ha de rúcula, também estabelecidas 0 DAT da chicória. Ainda de acordo com a Tabela 2, nota-se que a receita líquida do consórcio estabelecido com a semeadura da rúcula 20 DAT da chicória é semelhante à receita líquida da monocultura da chicória, mesmo o índice EUA de 1,31 atestando maior eficiência de uso da área.

Em síntese, todos os consórcios avaliados demonstram ser, do ponto de vista do EUA, viáveis. Contudo, considerandose os índices econômicos, receita líquida e taxa de retorno, além do próprio EUA, recomenda-se o cultivo consorciado de chicória e rúcula com o plantio das espécies no mesmo dia.

\section{REFERÊNCIAS}

ANDRIOLLI I; CENTURION JF. 1999. Levantamento detalhado dos solos da Faculdade de Ciências Agrárias e Veterinárias de Jaboticabal. In: CONGRESSO BRASILEIRO DE CIÊNCIAS DO SOLO, 199. Brasília. Anais... Brasília: Sociedade Brasileira de Ciências do Solo, 32 p. (CD-ROM)
BASSO DG. 2000. Efeito do consórcio sobre a produtividade das culturas de rúcula $e$ rabanete. 35p. (Monografia graduação).

CECÍlLIO FILHO AB; MAY A. 2002. Produtividade das culturas de alface e rabanete em função da época de estabelecimento do consórcio, em relação a seus monocultivos. Horticultura Brasileira 20: 501-504.

CECÍlIO FILHO AB.; TAVEIRA MCGS; GRANGEIRO LC. 2003. Productivity of beet and roquette cultivation as function of time of establishing intercropping. Acta Horticulturae 607: 91-95.

CECÍLIO FILHO AB. 2005. Cultivo consorciado de hortaliças: desenvolvimento de uma linha de pesquisa. Jaboticabal: UNESP/FCAV, 135p. (Tese livre-docência).

COSTA CC; CECÍlIO FILHO AB; GRANGEIRO LC. 2003a. Produtividade de cultivares de alface em função da época de estabelecimento do consórcio com rúcula, no outono-inverno de Jaboticabal-SP. Horticultura Brasileira 21: suplemento CDROM.

COSTA CC; CECÍlIO FILHO AB; GRANGEIRO LC. 2003b. Produtividade de cultivares de alface em função da época de estabelecimento do consórcio com rúcula, na primavera de Jaboticabal-SP. Horticultura Brasileira 21: suplemento CD-ROM.

FUNDAÇÃO GETÚLIO VARGAS - FGV. Índices gerais de preços: IGP-DI. Disponível em: <http://www.fgv.br/ índices>. Acesso em: 12 out. 2005.

NARDIN RR; CATELAN F; CECÍLIO FILHO AB. 2002a. Efeito do cultivo intercalado de rúcula e beterraba estabelecida por semeadura direta, sobre as produtividades das culturas. Horticultura Brasileira 20:suplemento CDROM.
NARDIN RR; CATELAN F; CECÍLIO FILHO AB. 2002b. Efeito da consorciação sobre as produtividades de rúcula e de beterraba estabelecidas por transplantio de mudas. Horticultura Brasileira 20:suplemento CDROM.

REZENDE BLA; COSTA CC; CECÍLIO FILHO AB; MARTINS MIEG; SILVA GS. 2005. Análise econômica de cultivos consorciados de alface e americana $\mathrm{x}$ rabanete: um estudo de caso. Horticultura Brasileira 23: 853-858.

REZENDE BLA; CECÍlIO FILHO AB; FELTRIM AL; COSTA CC; BARBOSA JC. 2006. Viabilidade da consorciação de pimentão com repolho, rúcula, alface e rabanete. Horticultura Brasileira 24: 36-41.

TRANI PE; PASSOS FA; AZEVEDO FILHO JA. 1997. Alface, almeirão, chicória, escarola, rúcula e agrião d'água. In: RAIJ, B; CANTARELLA H; QUAGGIO JA; FURLANI AMC. Recomendação de adubação e calagem para o Estado de São Paulo. Campinas: IAC. p.168-169. (Boletim Técnico, 100).

WILLEY RW. 1979. In Tercropping: its importance and research needs. 1. Competition and yied advantages. Field Crops Abstract 32: 1-10.

YOKOTA MS. 2002. Os mecanismos de comercialização e os canais de distribuição na cadeia produtiva da alface em Mogi das Cruzes-SP. 2002. 119p. Porto Alegre: UFRGS (Tese mestrado). 